\title{
A incompletude dos contratos de ônibus nos tempos da COVID-19
}

\author{
Gregório Costa Luz de Souza Lima ${ }^{1}$ \\ Gabriel Stumpf Duarte de Carvalho \\ Miguel Zobaran Figueiredo ${ }^{3}$ \\ 1 Universidade Federal do Rio de Janeiro / Programa de Engenharia de Transportes, Rio de Janeiro / RJ - Brasil \\ ${ }^{2}$ Instituto Superior Técnico de Lisboa / Departamento de Engenharia Civil, Arquitetura e Georrecursos, Lisboa - Portugal \\ ${ }^{3}$ Fundação Getulio Vargas / Centro de Estudos em Regulação e Infraestrutura, Rio de Janeiro / RJ - Brasil
}

\begin{abstract}
A pandemia da COVID-19 impõe sérios desafios ao setor de transporte público por ônibus. A queda da demanda em razão do isolamento social, a intensificação dos procedimentos de higienização, a aquisição de equipamentos de proteção individual e as restrições de lotação dos veículos ameaçam a viabilidade econômico-financeira do transporte coletivo brasileiro. A pandemia da COVID-19 pode ser caracterizada como um evento de força maior, ensejando reequilíbrio econômico-financeiro dos contratos de concessão de transporte público por ônibus. Entretanto, esta solução precisa ser buscada conjuntamente, pelo poder público e pelas empresas de transporte urbano, para garantir os interesses e as necessidades de ambas as partes. Este artigo sugere ações estratégicas para que o transporte coletivo continue operando durante a pandemia e os acordos de reequilíbrio econômicofinanceiro estejam alinhados com o interesse público. A superação das incertezas e consequências causadas pela pandemia exige a criação de relações de confiança e apoio mútuo entre inciativa privada (operadores) e governo.

Palavras-chave: COVID-19; transporte público; reequilíbrio econômico-financeiro; contratos.
\end{abstract}

\section{La incompletitud de los contratos de autobús en tiempos de COVID-19}

La pandemia de COVID-19 impone desafíos serios para el sector de transporte público por autobús. La caída de la demanda en función de las medidas de aislamiento social, la intensificación de los procedimientos de higiene, la adquisición del equipo de protección para los trabajadores y las restricciones en cuanto al número de pasajeros por vehículo amenazan la viabilidad económica-financiera del transporte colectivo brasileño. La pandemia de COVID-19 se puede caracterizar como acontecimiento de fuerza mayor que propicie el reequilibrio económico-financiero de contratos de concesión de transporte público por autobús. Sin embargo, esta solución debe buscarse en forma conjunta, por el gobierno y las empresas de transporte, para garantizar los intereses y las necesidades de ambas partes. Este artículo sugiere acciones estratégicas para que el transporte colectivo continúe funcionando durante la pandemia y los acuerdos de reequilibrio económico-financiero se alineen con el interés público. La superación de las incertidumbres y consecuencias de la pandemia requiere la creación de relaciones de confianza y apoyo mutuo entre la iniciativa privada (operadores) y los gobiernos.

Palabras clave: COVID-19; transporte público; equilibrio económico-financiero; contratos.

\section{Incomplete contracts for bus service during the COVID-19 pandemic: consequences and proposals}

The COVID-19 pandemic poses serious challenges for the public bus service. The fall in demand due to social distancing measures, the intensification of hygiene procedures, the acquisition of personal protective equipment, and restrictions on vehicle capacity threaten the financial viability of Brazilian public transportation. The COVID-19 pandemic may be characterized as a force majeure event, giving rise to an economic-financial balancing of public bus service contracts. However, this solution must be built by the public administration and transport companies to guarantee the interests and needs of both parties. Therefore, this article offers strategies to continue operating the service during the pandemic and to achieve economic and financial equilibrium protecting the public interest. Overcoming the uncertainties and consequences caused by the pandemic requires relationships of trust and mutual support between the private sector (operators) and government.

Keywords: COVID-19; public transport; economic and financial equilibrium; contracts. 


\section{INTRODUÇÃO}

A pandemia da COVID-19 paralisou as atividades diárias não essenciais. Entre as medidas adotadas por estados e municípios brasileiros para evitar a disseminação do novo coronavírus, está o isolamento social horizontal voluntário, ou mandatório, de pessoas que não desempenham atividades essenciais. As medidas que limitam a circulação da população, no entanto, não podem ser confundidas pelos gestores públicos com a paralisação do transporte coletivo (Lima, Schechtman, Brizon, \& Figueiredo, 2020).

A despeito do número reduzido de pessoas se deslocando, a interrupção dos serviços de transporte público não parece ser uma opção. Em estudo conduzido nas 20 maiores cidades brasileiras, Pereira et al. (2020) estimaram que: há mais de 228 mil pessoas acima de 50 anos que residem a, no mínimo, 30 minutos de caminhada de um atendimento do SUS apto a atender casos suspeitos do novo coronavírus; $41 \%$ da população de baixa renda e acima de 50 anos moram a uma distância maior do que $5 \mathrm{~km}$ de unidades de saúde capazes de fazer a internação de pacientes em estado grave. $\mathrm{Na}$ Região Metropolitana de São Paulo, 55,7\% das viagens por motivo de saúde ocorrem por transporte coletivo (Metrô-SP, 2019). Assim, por cumprir um papel essencial para pessoas que buscam assistência médica (Lima et al., 2020; Union Internationale des Transport Publics [UITP], 2020), o transporte público não pode ser paralisado.

Embora importantes para a redução da disseminação da COVID-19, as medidas de isolamento social impactam consideravelmente a economia, em especial o setor de transporte (Associação Nacional das Empresas de Transporte Urbano [NTU], 2020; De Vos, 2020; Lima et al., 2020). Com o grande número de pessoas trabalhando remotamente e o cancelamento da maioria das atividades de lazer, a queda no número de viagens é inevitável. Espera-se que essa seja apenas uma situação temporária e que o retorno às atividades fora de casa resultem no aumento da demanda de viagens quando as restrições de circulação forem suspensas. Contudo não se sabe quanto tempo essas medidas durarão e se virão ondas subsequentes de contágio (De Vos, 2020).

Pode ocorrer ainda a permanência do temor do contato social quando as regras de distanciamento social não estiverem mais em vigor (De Vos, 2020). Por considerar o transporte coletivo um terreno propício à proliferação do vírus, onde é difícil preservar-se do contato com outros passageiros, indivíduos podem evitar a sua utilização (Troko et al., 2011; UITP, 2020). As pessoas com acesso a carro podem estar inclinadas a dirigir mais, por entender que o carro as "protege" do contato com outros viajantes (De Vos, 2020). É possível, ainda, que usuários habituais do transporte público passem a utilizar táxi e serviços de transporte por aplicativo, especialmente aqueles sem restrições financeiras (De Vos, 2020).

Outro fator que impactará na demanda do transporte coletivo é a migração de usuários para o transporte ativo (bicicleta e caminhada) - para viagens curtas -, em razão de ele restringir o contato social durante os deslocamentos (De Vos, 2020). O poder público pode estimular a caminhada e o ciclismo (temporariamente) alocando espaços menos utilizados nas ruas para ciclistas e pedestres (King \& Krizek, 2020). Cidades ao redor do mundo (Berlim, Viena, Filadélfia, Vancouver, Bogotá e Cidade do México) já estão transformando faixas de estacionamento em calçadas e ciclovias (Laker, 2020).

Assim, a queda de demanda do transporte coletivo durante e após o isolamento social, juntamente com a intensificação das medidas de higiene, a compra de equipamentos de proteção individual e as restrições de lotação dos veículos (aumento da oferta desproporcionalmente à demanda habitual) 
impõem dificuldades financeiras aos operadores (Badger, 2020; Foye, 2020; Lima et al., 2020; NTU, 2020). Há um trade-off nas decisões dos operadores e poder público entre conter os impactos financeiros no sistema de transporte reduzindo a oferta e manter a operação dos serviços com uma lotação adequada para evitar a propagação do vírus. Entretanto, mesmo que haja a possibilidade de adaptar a operação para reduzir as despesas, existe um elevado custo fixo a ser coberto por uma receita que poderá não existir. Nos locais em que houve a interrupção do transporte coletivo pelo poder público, os custos fixos e a inexistência de receitas operacionais continuarão a impor dificuldades financeiras aos operadores, que podem não conseguir retomar a operação com o fim do distanciamento social. Em média 50\% das despesas dos operadores de transporte coletivo por ônibus são destinadas ao pagamento de pessoal (NTU, 2020).

Os contratos de ônibus brasileiros, em grande parte, são caracterizados pela alocação dos riscos financeiros nos operadores, que, em geral, assumem os riscos de custos de operação e de receita. Em situações como a crise da COVID-19, contudo, não é plausível que os operadores assumam esses riscos sozinhos. A pandemia do novo coronavírus pode ser caracterizada como um evento de força maior, ou evento fortuito, ensejando em reequilíbrio econômico-financeiro dos contratos (Consultoria Jurídica junto ao Ministério da Infraestrutura [CONJUR], 2020). Ademais, mesmo os sistemas subsidiados pelo governo, em que o risco de receita é compartilhado ou alocado no ente público, podem enfrentar dificuldades financeiras. A atividade econômica reduzida por conta da COVID-19 pode afetar a arrecadação de impostos e, consequentemente, o repasse das subvenções para o transporte coletivo.

O desafio da manutenção dos serviços no curto prazo e da recomposição do equilíbrio dos contratos no médio e longo prazo exigem uma resposta célere da administração pública. A situação é especialmente crítica para operadores menores (Fletcher et al., 2014), que possuem pouca liquidez para sustentar os prejuízos por um período prolongado. De acordo com a NTU (2020), há empresas de transporte público falindo no país por conta da crise. Neste cenário, empresas com dificuldades de caixa podem decretar falência ou ser absorvidas por empresas maiores e com maior capacidade financeira. Logo, se nada for feito, espera-se uma concentração maior do mercado, que, do ponto de vista da competição e da contestabilidade, é indesejável (Gwilliam, 2008).

A solução deste imbróglio, no entanto, ainda não foi encontrada e deve ser buscada de acordo com as especificidades locais. A variabilidade da capacidade dos órgãos reguladores de transporte público é um elemento que pode influenciar na elaboração de medidas de solução. Enquanto cidades de maior porte geralmente apresentam entidades reguladoras independentes, com recursos financeiros e técnicos suficientes, outras cidades não possuem entidade especializada e a regulação ocorre basicamente por contrato. Em um contexto de assimetria de informação e vulnerabilidade à captura regulatória (Rolim, Brasileiro, \& Santos, 2010), empresas com maior poder no mercado podem se valer da sua condição para auferir vantagens durante os processos de reequilíbrio econômico-financeiro. $\mathrm{Ou}$, ainda, em um ambiente de baixa segurança regulatória, empresas estão sujeitas a fornecer um serviço mínimo durante a crise, na expectativa de serem recompensadas por um futuro processo de reequilíbrio econômico-financeiro. Entretanto, por inércia (ou inexistência) do regulador, este processo pode não ocorrer em um prazo razoável e justo para restaurar a saúde financeira das empresas.

À luz dos impactos causados pela pandemia da COVID-19 na operação dos serviços públicos urbanos de ônibus, este artigo objetiva orientar a renegociação dos respectivos contratos, de forma a garantir o interesse público e o justo reequilíbrio econômico-financeiro desses serviços. $\mathrm{O}$ artigo está organizado em quatro seções, além desta introdução. A seção seguinte apresenta os impactos da 
COVID-19 no setor de transporte público por ônibus e as ações tomadas pela administração pública para contê-los. A terceira seção caracteriza sucintamente o setor de ônibus no Brasil. A seção de número quatro, por sua vez, trata da incompletude dos contratos de ônibus no Brasil e explicita a necessidade do reequilíbrio econômico-financeiro. Por fim, a quinta seção recomenda ações estratégicas para o reequilíbrio dos contratos, e apresenta as conclusões do trabalho.

\section{IMPACTOS E AÇÕES DE RESPOSTA A COVID-19 NO SETOR DE TRANSPORTE PÚBLICO POR ÔNIBUS NO BRASIL}

O principal impacto da COVID-19 no setor de transporte público por ônibus advém das medidas de isolamento social voluntárias ou mandatórias adotadas em cidades e estados brasileiros. Comparativatemente a outros serviços públicos, como energia elétrica, que teve queda de demanda na faixa de 14\% (Câmara de Comercialização de Energia Elétrica [CCEE], 2020), estima-se que a redução do número de passageiros no transporte coletivo por ônibus varie entre 65 e $80 \%$ (Figura 1) (Lima et al., 2020; Moovit, 2020; NTU, 2020).

\section{FIGURA 1 QUEDA DE DEMANDA DE PASSAGEIROS NOS SISTEMAS DE TRANSPORTE PÚBLICO POR ÔNIBUS NO BRASIL}

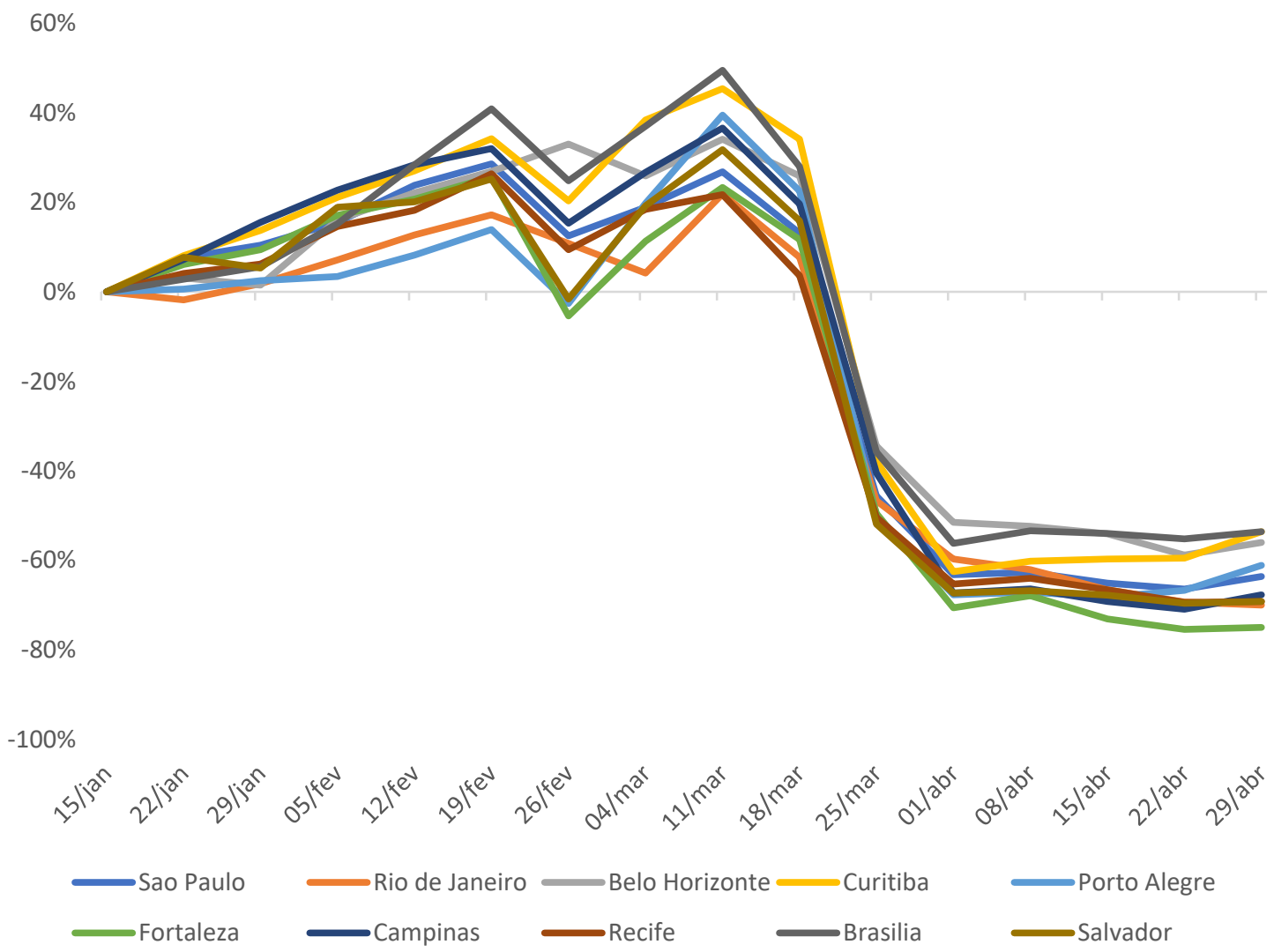

Fonte: Moovit (2020). 
Diante da redução de passageiros, algumas empresas operadoras, mediante permissão dos órgãos gestores, reduziram a frota e a frequência das linhas de ônibus. Apesar da autorização para adaptação da oferta, alguns municípios emitiram decretos limitando a lotação dos veículos com objetivo de prevenir o contágio da doença (ex: Porto Alegre - RS). O ajuste da oferta é importante não só para conter os danos financeiros, mas também para garantir que os trabalhadores permaneçam saudáveis e sejam capazes de manter o sistema funcionando (Goldbaum, 2020). Segundo a NTU (2020), a redução da oferta dos serviços no país foi de $25 \%$ em média. Ademais, houve a paralisação total dos serviços de transporte público por ônibus em 180 municípios (NTU, 2020), 175 deles no Estado de Santa Catarina. Os decretos referentes a algumas das medidas citadas estão sumarizados no Quadro 1.

\section{QUADRO 1 DECRETOS PÚBLICOS QUE INFLUENCIAM 0 NÍVEL DE SERVIÇO DO TRANSPORTE PÚBLICO POR ÔNIBUS}

\begin{tabular}{|c|c|c|}
\hline Medida & Município/Estado & Processo \\
\hline \multirow{5}{*}{$\begin{array}{l}\text { Adequação da oferta à } \\
\text { demanda }\end{array}$} & São Paulo & Decreto № 59.283 de 16 de Março de 2020 \\
\hline & São Paulo & Comunicado Externo ARTESP DPL Nº3/2020 \\
\hline & Espírito Santo & Norma Complementar CETURB/ES Nº 003/2020 \\
\hline & Espírito Santo & Norma Complementar CETURB/ES Nº 004/2020 \\
\hline & Teresina & Decreto No 19.548 de 29 de Março de 2020 \\
\hline \multirow[t]{6}{*}{ Redução da lotação } & Porto Alegre & Decreto № 20.549 de 22 de Abril de 2020 \\
\hline & Rio Grande do Sul & Decreto № 55.154 de $1^{\circ}$ de Abril de 2020 \\
\hline & Rondônia & Decreto № 24.979 de 26 de Abril de 2020 \\
\hline & Goiânia & Decreto № 951 de 28 de Abril de 2020 \\
\hline & Campo Grande & Decreto No 14.271 de 29 de Abril de 2020 \\
\hline & Palmas & Decreto № 1.863 de 22 de Março de 2020 \\
\hline \multirow{5}{*}{$\begin{array}{l}\text { Restrição do transporte } \\
\text { público intermunicipal / } \\
\text { metropolitano }\end{array}$} & Rio de Janeiro & Portaria Detro/Pres № 1.523 de 06 de Abril de 2020 \\
\hline & Rio de Janeiro & Resolução Conjunta SEDEERI/SETRANS No 11 de 07 de Abril de 2020 \\
\hline & Belo Horizonte & Decreto № 17.326 de 6 de Abril de 2020 \\
\hline & Pernambuco & Decreto № 48.834 de 20 de Março de 2020 \\
\hline & Acre & Decreto $N^{0} 5.812$ de 17 de Abril de 2020 \\
\hline \multirow{3}{*}{$\begin{array}{l}\text { Suspensão do transporte } \\
\text { público }\end{array}$} & João Pessoa & Decreto № 9.472 de 17 de Abril de 2020 \\
\hline & Florianópolis & Decreto № 21.357 de 19 de Março de 2020 \\
\hline & Florianópolis & Portaria No. 008/Smpu/Gab/2020 \\
\hline \multirow{2}{*}{$\begin{array}{l}\text { Suspensão do transporte } \\
\text { público intermunicipal/ } \\
\text { metropolitano }\end{array}$} & Rio de Janeiro & Decreto No 47.052 de 29 de Abril de 2020 \\
\hline & Bahia & Decreto No 19.635 de 14 de Abril de 2020 \\
\hline
\end{tabular}

Fonte: Elaborada dos autores. 
Entre outros impactos da COVID-19 no setor, estão: falência de empresas (Guarulhos/SP), demissões em massa, suspensão dos contratos trabalhistas (Florianópolis/SC, Campina Grande/ $\mathrm{PB}$, Rio de Janeiro/RJ, Itabuna/BA) e redução das jornadas de trabalho (São Paulo/SP). Em alguns municípios foram adotadas estratégias de parcelamento dos salários (Belo Horizonte/MG, Goiânia/ GO) e revezamento das escalas de trabalho (Manaus/AM, Americana/SP). De acordo com a NTU (2020), caso seja mantida a redução média da oferta da ordem de $25 \%$, cerca de 62 mil motoristas, 50 mil cobradores e outros 12 mil profissionais das empresas de ônibus serão demitidos. O setor de transporte público por ônibus no Brasil emprega direta e indiretamente cerca de 1,8 milhão de pessoas, e totaliza um faturamento anual da ordem de R\$ 42,1 bilhões (NTU, 2020).

Muitas das ações tomadas em relação à mão de obra apoiam-se na Medida Provisória (MP) 936 (2020). Esta MP tem por objetivo preservar o emprego e a renda, garantir a continuidade das atividades empresariais e laborais e reduzir o impacto social da COVID-19. Entre as medidas previstas, estão o pagamento de um benefício emergencial de renda em caso de redução da jornada de trabalho e de salário, ou suspensão temporária de contrato de trabalho. Para a redução da jornada de trabalho e de salários, deve ser preservado o valor de salário-hora do trabalho, sendo a redução dentro dos percentuais de $25 \%, 50 \%$ ou $75 \%$. Ademais, a suspensão do contrato de trabalho é limitada ao período máximo de 60 dias, durante o qual o empregado continua recebendo os benefícios concedidos pelo empregador. As medidas se aplicam a empregados com salário mensal igual ou inferior a $\mathrm{R} \$ 3.135,00$ ou com diploma de nível superior e que recebam salário mensal igual ou superior a duas vezes o limite máximo de benefícios do Regime Geral de Previdência Social (RGPS).

Vale notar, ainda, que operadores podem ajustar os salários dos empregados apoiados no Art. 503 da Lei $n^{\circ} 5.452$ (1943). Segundo o artigo, em caso de força maior ou prejuízos devidamente comprovados, é licita a redução geral dos salários dos empregados da empresa, proporcionalmente aos salários de cada um, não podendo, entretanto, a redução ser superior a $25 \%$ (vinte e cinco por cento), respeitado, em qualquer caso, o salário mínimo da região.

O prejuízo total estimado da redução de demanda provocada pela pandemia do novo coronavírus foi de R $\$ 2,5$ bilhões (NTU, 2020) no primeiro mês do isolamento. Este é o valor mensal demandado por uma das propostas de superação da crise. A NTU, juntamente com o Fórum Nacional de Secretários e Dirigentes Públicos de Mobilidade Urbana e Associação Nacional de Transporte Público (ANTP), apoiados pela Frente Nacional de Prefeitos (FNP), propuseram a criação do Programa Transporte Social ao Ministério da Economia, com a destinação de R 2,5 bilhões mensais por parte do governo para a compra de créditos eletrônicos de passagem, enquanto perdurar a crise decorrente da COVID-19.

A ideia por trás do Programa Transporte Social é a pactuação de um nível mínimo de serviço a ser prestado durante a pandemia pelas três esferas governamentais (federal, estadual e municipal). Tal nível mínimo seria estabelecido em termos percentuais e o limite da redução do número de ônibus em operação, previsto nos respectivos contratos entre o poder concedente local e os respectivos concessionários de transporte (NTU, 2020). Os créditos eletrônicos seriam utilizados nos programas de assistência social do Governo Federal e distribuídos mensalmente por um período de 12 meses contados após o término do período de pactuação. Outra proposta feita pela NTU (2020) seria a redução em $50 \%$ do preço do óleo diesel cobrado pela Petrobrás.

Existem também iniciativas municipais para garantir a operação dos serviços de transporte público. Na cidade de Belo Horizonte, a prefeitura efetua pagamentos semanais na ordem de 
R \$3,5 milhões aos operadores, referentes ao adiantamento dos vales-transporte dos seus funcionários. Em Curitiba, há um Projeto de Lei Ordinária que propõe instituir um regime emergencial de operação e custeio do transporte público. O Projeto de Lei prevê repasses às concessionárias para cobrir exclusivamente custos administrativos, de folha de pagamento, plano de saúde, seguro de vida, cesta básica e tributos. A ideia é que os repasses garantam a manutenção essencial dos serviços em níveis mínimos operacionais.

Embora iniciativas como as destacadas sejam importantes para a manutenção do sistema de transporte público neste momento, é importante ponderar a respeito dos efeitos em médio e longo prazos que a concessão desses tipos de subvenção terá sobre os cofres públicos. Em virtude da pandemia, ações da administração pública que antes levariam meses para serem tomadas, estão sendo tomadas em questão de dias (Fletcher et al., 2014). Contudo, em razão da velocidade da tomada de decisão, é possível que não haja a previsão na Lei Orçamentaria Anual para o empenho de recursos públicos, o que, por sua vez, pode implicar realocação de recursos e a não cobertura de alguma outra pauta, igualmente importante.

\section{OS SERVIÇOS DE ÔNIBUS URBANOS NO BRASIL}

Os sistemas de ônibus no Brasil foram efetivamente consolidados a partir das décadas de 1960 e 1970, quando os serviços surgiram sem qualquer intervenção do poder público no planejamento de linhas e horários. Portanto ficou a cargo dos operadores compreender as demandas da população e criar as linhas que poderiam ser mais rentáveis. Enquanto as redes de bondes eram postas de lado, os municípios começaram a criar empresas de transporte público para impor políticas regulatórias às operadoras de ônibus, que eram forçadas a fundir-se e a padronizar os tipos de veículo. Assim teve início o desenvolvimento das empresas de ônibus modernas e formais no Brasil (Almeida Motta, Silva, \& De Sequeira Santos, 2013).

Atualmente a Constituição Federal (1988) estabelece, pelo artigo $n^{\circ}$ 175, que todos os serviços públicos precisam ser prestados pelos órgãos públicos ou ser delegados ao setor privado mediante licitação, resultando, assim, em um contrato. A concessão ou permissão para a prestação de serviços públicos por empresas privadas está sujeita a critérios de licitação competitiva. De acordo com a Lei no 8.987 (1995), os critérios de adjudicação são o menor valor da tarifa de serviço público a ser fornecida; a maior oferta, nos casos de pagamento à autoridade concedente pela concessão; a melhor oferta técnica, com o preço definido no edital; ou uma combinação destes (Gomide \& Carvalho, 2016).

Infelizmente, de acordo com Rolim et al. (2010), as indústrias locais de ônibus têm se concentrado estruturalmente com fortes evidências de captura regulatória. Este processo remonta às décadas de 50 e 60, quando os proprietários de frotas, com licenças de caráter precário, expandiam suas operações incorporando concorrentes e aumentando seu território e poder de mercado. Em muitos casos, verticalizaram suas atividades, atuando em financiamento, comercialização e manutenção de veículos (Mesentier, Malburg, Souza, Amicci, \& Santos, 2018).

Rolim et al. (2010) alegam que a maioria dos contratos existentes não é resultado de licitações públicas, e que o direito de operar foi automaticamente renovado, sem ser submetido a processos competitivos. Assim, a concorrência pelo mercado tem sido a exceção e não a regra. De acordo com Gómez-Lobo e Briones (2014), nos países em desenvolvimento, as instituições padecem com a falta de recursos humanos e a baixa capacidade de enforcement, os sistemas jurídicos são lentos, o acesso 
aos mercados financeiros é limitado e os recursos orçamentários para investimentos e subsídios são escassos. Laffont (2005) complementa afirmando que os países em desenvolvimento geralmente sofrem com a falta de tecnologia atualizada, ausência de sistemas de contabilidade e auditoria bem desenvolvidos devido à falta de programas de treinamento adequados para funcionários públicos e à corrupção, frequentemente presente nas relações entre os setores privado e público.

\section{A INCOMPLETUDE DOS CONTRATOS E A NECESSIDADE DE RENEGOCIAÇÃO}

Contratos são naturalmente incompletos, apresentando, grosso modo, requisitos vagos e omissões com relação a muitos aspectos fundamentais (Tirole, 1999). É também impossível, ou por vezes muito custosa, a previsão de todas as contingências e do curso de ação a ser seguido em cada cenário ou estado da natureza. Esta dificuldade, portanto, é um dos principais argumentos a favor de contratos incompletos (por natureza) e com maior flexibilidade (Domingues \& Zlatkovic, 2015). Muitos problemas que surgem em licitações públicas, por exemplo, são relacionados à necessidade de adaptações ex-post a contingências imprevistas nos contratos (De Brux \& Desrieux, 2014).

No mercado de ônibus urbanos, os contratos de concessão podem ser categorizados majoritariamente em três grupos (Cambini \& Filippini, 2003; Roy \& Yvrande-Billon, 2007; Van de Velde, Beck, Van Elburg, \& Terschüren, 2008; Organização para a Cooperação e Desenvolvimento Econômico [OCDE], 2013).

Nos contratos cost-plus (também chamados contratos de gestão), a operadora é paga por todas as suas despesas previamente permitidas, e recebe um pagamento adicional para garantir um lucro justo e razoável. Neste tipo de contrato, tanto o risco de produção (operação) quanto o risco de receita são assumidos pela autoridade.

Nos contratos gross-cost, as empresas concorrem para receber um valor específico para cobrir seus custos (incluindo algum nível de lucro), enquanto as autoridades locais mantêm as receitas tarifárias e suportam o risco relativo. Além de reduzir o risco enfrentado pelo operador vencedor, este tipo de contrato também tem a vantagem de reduzir a assimetria de informação entre os novos operadores e os incumbentes no que diz respeito ao nível de receitas.

Os contratos net-cost, anteriormente chamados contratos de risco total, são aqueles nos quais o operador assume todos os riscos operacionais (custos e receitas). Neste arranjo, o pagamento representa o saldo esperado das receitas menos os custos de produção. Ao final do período contábil, se a diferença real entre os custos operacionais e a receita não corresponder ao déficit previsto, o operador assume o prejuízo. No caso de muitas capitais brasileiras, como as operações possuem grande magnitude e potencial de lucro, é comum ver um pagamento de outorga pelo operador vencedor à autoridade de transporte pelo direito de exclusividade, como forma de reduzir o lucro para um valor razoável e garantir o interesse público.

A pandemia causada pelo coronavírus pode ser enquadrada como um caso de força maior nos contratos de licitação de ônibus (CONJUR, 2020). Seria impossível prever este acontecimento durante o desenvolvimento dos processos licitatórios. Os contratos de ônibus nas cidades brasileiras, tanto de tipologia net-cost como gross-cost, não consideram medidas de adaptação das operações em caso de uma pandemia. Como dito anteriormente, a atual pandemia afeta diretamente a operação das empresas, causando distúrbios na oferta e, principalmente, afetando as receitas dos operadores. Para manter as operações - mesmo que reduzidas -, garantir a liquidez das empresas e a manutenção dos 
contratos de trabalho, é fundamental que o poder público e os operadores negociem um reequilíbrio econômico-financeiro dos contratos e cheguem a um comum acordo de forma célere.

Conforme estabelece o inciso XXI do art. 37 da Constituição Federal (1988), o equilíbrio econômico financeiro do contrato corresponde à manutenção das "condições efetivas da proposta". Disto decorre, primeiramente, que a equação econômico-financeira original do contrato está associada às circunstâncias presentes no momento da apresentação da proposta pelo licitante vencedor. Em segundo lugar, é preciso que haja algum fato superveniente à proposta que justifique a necessidade de reequilíbrio. Em relação à quebra da equação econômico-financeira, Justen (2003, p. 390) afirma que:

A quebra da equação econômico-financeira pode ocorrer a qualquer instante e configurar-se-á sempre que se produzir alguma espécie de evento superveniente extraordinário, imprevisível ou de consequências incalculáveis, que amplie os encargos ou reduza as vantagens originalmente assumidas pela parte.

Além disso, o insucesso do empreendimento não prejudica apenas o concessionário ou arrendatário, mas também os usuários do serviço público. Há então um interesse público na estabilidade dos contratos de concessão de serviço público (CONJUR, 2020). Entretanto, no cenário atual de crescentes preocupações políticas sobre conluio e corrupção, toda negociação ex-post deve ser acompanhada por processos transparentes que se baseiem em métricas mensuráveis associadas a conscientização e divulgação pública (Merkert, Preston, Melkersson, \& Link, 2018).

Considerando a incompletude dos contratos de ônibus, a gravidade da situação causada pela COVID-19, o receio de conluio e captura regulatória, é imprescindível que qualquer medida adotada para regularizar a situação seja estabelecida de forma transparente e aberta ao público. A abertura de dados sobre os atos e recursos financeiros da administração pública e das empresas prestadoras de serviço permite à população identificar possíveis fraudes e atos de corrupção que venham prejudicar a eficiência econômica e o bem-estar social. Como há risco de assimetria de informação, também é fundamental que a entidade reguladora tenha um olhar crítico sobre toda prestação de contas e operações realizadas tendo em vista aferir os reais desbalanceamentos na situação financeira das companhias.

\section{RECOMENDAÇÕES E CONCLUSÕES}

As medidas de distanciamento social impostas para conter a disseminação da COVID-19 não podem ser entendidas como a suspensão dos serviços de transporte público. O transporte coletivo cumpre um papel fundamental ao fornecer acesso as pessoas que buscam assistência médica. Além disso, existe uma gama de profissionais trabalhando presencialmente neste momento que dependem unicamente do serviço público de transporte para se deslocar. Contudo a manutenção do transporte coletivo durante a crise enfrenta desafios.

Devido à natureza da maioria dos contratos de ônibus no Brasil ser caracterizada pela alocação do risco da demanda nos operadores, os sistemas de transporte público podem sofrer efeitos desproporcionais em virtude da pandemia. A queda da demanda, a intensificação dos procedimentos de sanitização, a aquisição de equipamentos de proteção para os trabalhadores e as restrições de lotação dos veículos durante o isolamento social reduzem a receita e impõem custos extras aos operadores. 
Nas cidades em que o sistema de transporte público foi paralisado, os custos fixos, em especial com pessoal, ainda precisam ser cobertos por uma receita operacional que deixou de existir. Mesmo nos sistemas de transporte em que o risco de receita é compartilhado e que há subsídios para os operadores, a redução da atividade econômica pode reduzir a arrecadação das prefeituras e, consequentemente, este prejuízo pode se refletir no repasse das subvenções. Ainda, com o relaxamento do isolamento social, é possível que os hábitos de utilização do transporte público se alterem, resultando em um número de passageiros inferior ao habitual. Todos esses fatores ameaçam a viabilidade financeira da operação dos serviços de transporte coletivo. Embora a adaptação da oferta seja uma medida capaz de amenizar o déficit financeiro dos operadores, existe um alto custo fixo que precisa ser coberto e amortizado.

As consequências da crise gerada pela COVID-19 já são perceptíveis nos sistemas de transporte público pelo país. Entre os impactos, verificam-se: a falência de empresas, demissões em massa, suspensão dos contratos trabalhistas e redução da jornada de trabalho. A situação é ainda mais crítica para empresas de menor porte e com pouca liquidez para sustentar os prejuízos por um prazo prolongado. A falência das empresas pequenas possui, ainda, efeitos de segunda ordem, como a concentração do mercado e o consequente comprometimento da competição e contestabilidade dos mercados.

Embora o risco de demanda seja alocado nos operadores em muitos dos contratos, não é plausível que as empresas arquem com os prejuízos (diminuição das receitas) sozinhas. Os contratos, em geral, são caracterizados pela sua incompletude. Eventos como a pandemia da COVID-19 não poderiam ser previstos nos contratos, sejam eles net-cost ou gross-cost. Ademais, mesmo que o evento em questão fosse previsto com elevado grau de confiabilidade, a alocação do risco continuaria prejudicada pela ausência de instrumentos adequados; as seguradoras, por exemplo, não contemplavam a cobertura dos impactos de pandemias até então. Tais produtos, caso sejam de fato desenvolvidos, seriam potencialmente muito custosos para os compradores de proteção.

Portanto a crise gerada pelo novo coronavírus configura um evento de força maior, justificando, assim, o reequilíbrio da situação econômico-financeira acordada em contrato entre operadores e poder público. Vale ressaltar que existe um interesse público na estabilidade dos contratos de ônibus. Por se tratar de serviço público essencial, a falência das empresas não as prejudica somente, mas também os usuários do serviço. Além disso, a continuidade dos serviços contribui para a retomada do crescimento econômico após a pandemia (Foye, 2020).

Tendo em vista a continuidade da operação, a garantia da liquidez e a manutenção dos contratos das empresas de ônibus, é necessária uma resposta rápida da administração pública, elaborada juntamente com os operadores do serviço. Entretanto algumas características e variáveis regulatórias do setor podem dificultar o desenho de uma solução adequada neste momento.

Devido à variabilidade da capacidade regulatória entre cidades no país, o risco de captura regulatória é alto, principalmente em cidades menores, sem entidades reguladores e/ou com corpo técnico insuficiente e/ou pouco qualificado. Em um contexto de assimetria de informações, pouca capacidade de enforcement e baixa segurança regulatória, o risco de empresas de grande porte usarem seu poder de mercado para auferir vantagens nos processos de reequilíbrio econômico financeiro é grande. No entanto, a baixa capacidade técnica, inércia ou até mesmo inexistência, de agências reguladoras, juntamente com a pouca segurança regulatória, podem prejudicar operadores que mantiveram os serviços na expectativa de um reequilíbrio econômico-financeiro futuro. Assim, 
a transparência dos atos e recursos financeiros do poder público e das empresas reguladas são fundamentais neste momento para evitar que ocorram fraudes e atos de corrupção - prejudiciais à eficiência econômica e ao bem-estar social.

Considerando o cenário exposto e a necessidade inadiável de se reequilibrarem os contratos garantindo o interesse público, algumas ações/estratégias são recomendadas.

1. A prestação de contas por parte dos operadores deve ser detalhada com informações sobre toda mão de obra utilizada na operação e aqueles funcionários que foram desligados ou tiveram seus contratos interrompidos. Adicionalmente, deve-se divulgar detalhadamente a operação com os serviços realizados (linhas e horários), quantidade de quilômetros percorridos e custos envolvidos.

2. Em caso de ocorrência, as empresas devem apresentar todos os recursos emergenciais providos por qualquer esfera do governo, detalhando o montante, a forma (empréstimos, fundo perdido etc.) e a origem dos repasses.

3. O poder concedente e/ou entidade reguladora $\operatorname{deve}(\mathrm{m})$ exigir apresentação de relatório financeiro (fluxo de caixa, taxa interna de retorno etc.) comprovando o impacto financeiro nas empresas.

4. A transparência deve ser um mote dos processos de renegociação. Dessa forma, recomenda-se a divulgação de todos os dados, relatórios, processos e decisões em portal aberto (site) para o escrutínio da mídia e da população.

5. Na falta de recursos técnicos, as prefeituras podem contratar consultoria externa (empresas de consultoria privada, órgãos públicos especializados, instituições de ensino superior, câmaras de mediação e arbitragem etc.) para mediar a negociação.

6. Em casos emergenciais, é preferível que a prefeitura repasse os recursos necessários para que os operadores não suspendam os serviços, vindo depois a renegociar um ajustamento nas tarifas ou utilizar outra forma de reequilibrar as contas, caso ocorra uma sobrecompensação. Uma alternativa para municípios com dificuldades orçamentárias seria a busca por financiamento em bancos públicos, como o Banco Nacional do Desenvolvimento (BNDES) e a Caixa Econômica Federal. Recentemente o BNDES anunciou pacotes de socorro aos setores de aviação e de energia elétrica e já se discute a possibilidade de auxílio ao setor de mobilidade urbana.

7. No caso de a redução da demanda ser inferior ao planejado, após o relaxamento das medidas de isolamento social, operadores e reguladores devem pensar em reorganizar os serviços para garantir a prestação do serviço adequado e a viabilidade financeira.

É importante destacar que, tendo em vista garantir a manutenção da operação dos serviços, decisões devem ser tomadas de forma célere, porém cautelosa. Para a superação das incertezas e das consequências da pandemia, é fundamental que se criem relações de confiança e de apoio entre a iniciativa privada (operadores) e o poder público. Independentemente da solução adotada pelas Prefeituras, a transparência deve ser o alicerce da tomada de decisão.

Assim, este momento de crise, com suas respectivas ações de mitigação, constitui oportunidade única para a adoção de práticas de Governança Corporativa, já comuns em outras indústrias reguladas, para um incremento da participação social e transparência e para uma melhoria dos processos regulatórios, essenciais mesmo em tempos de normalidade. 


\section{REFERÊNCIAS}

Almeida Motta, R., Silva, P. C. M., \& Sequeira Santos, M. P. (2013). Crisis of public transport by bus in developing countries: a case study from Brazil. International Journal of Sustainable Development and Planning, 8(3), 348-361. Recuperado de https://doi. org/10.2495/SDP-V8-N3-348-361

Agência de Transporte do Estado de São Paulo. Comunicado Externo ARTESP DPL n. 3, de 2020. (2020). São Paulo, SP: Autor. Recuperado de http://www.artesp.sp.gov.br/Shared\%20 Documents/TransporteColetivo/Comunicados/ COMUNICADO-EXTERNO-DPL-03-2020.pdf

Associação Nacional das Empresas de Transporte Urbano. (2020, abril). Covid-19 e o Transporte Público por Ônibus: Impactos no Setor e Ações Realizadas. Brasília, DF: Autor. Recuperado de https://www.ntu.org.br/novo/upload/Publicacao/ Pub637231535674949776.pdf

Badger, E. (2020, 9 de abril). Transit Has Been Battered by Coronavirus. What's Ahead May Be Worse. The New York Times. Recuperado de https://www. nytimes.com/2020/04/09/upshot/transit-batteredby-coronavirus.html? searchResultPosition=2

Câmara de Comercialização de Energia Elétrica. (2020, abril). Acompanhamento do Consumo em Função da COVID-19. São Paulo, SP: Autor. Recuperado de https://www.ccee.org.br/ccee/ documentos/CCEE_654419

Cambini, C., \& Filippini, M. (2003). Competitive tendering and optimal size in the regional bus transportation industry: an example from Italy. Annals of Public and Cooperative Economics, 74(1), 163-182.

Constituição Federal de 1988. (1988). Brasília, DF. Recuperado de http://www.planalto.gov.br/ ccivil_03/constituicao/constituicao.htm

Consultoria Jurídica junto ao Ministério da Infraestrutura. (2020). Parecern. 261/2020/CONJURMINFRA/CGU/AGU. Consulta em tese. Covid-19. Reequilíbrio de contratos de concessão. Força Maior. Consultoria Jurídica junto ao Ministério da Infraestrutura, Gabinete da Consultoria Jurídica. Brasília: Felipe Nogueira Fernandes. Recuperado de: https://sapiens.agu.gov.br/documento/406894540

De Brux, J., \& Desrieux, C. (2014). To allot or not to allot public services? An incomplete contract approach. European Journal of Law and Economics, 37(3), 455-476. Recuperado de https:// doi.org/10.1007/s10657-012-9349-9

Decreto n. 951, de 28 de abril de 2020. (2020). Dispõe sobre medidas complementares de enfrentamento da crise provocada pela pandemia causada pelo novo coronavírus (COVID-19) nos serviços de transporte público coletivo e recomenda horários de funcionamento de estabelecimentos industriais, comerciais e de serviços, no âmbito do Município de Goiânia. Goiânia, GO. Recuperado de https:// sagresonline.com.br/wp-content/uploads/2020/04/ decreto_n_951.pdf

Decreto n. 1.863, de 22 de março de 2020. (2020). Altera o Decreto $\mathrm{n}^{\circ} 1.856$, de 14 de março de 2020, que declara situação de emergência em saúde pública no município de Palmas e dispõe sobre medidas de enfrentamento da pandemia provocada pelo coronavírus (COVID-19), nas partes que especifica. Palmas, TO. Recuperado de http://diariooficial.palmas.to.gov.br/media/ diario/2454-22-3-2020-22-18-59.pdf

Decreto n. 5.812, de 17 de abril de 2020. (2020). Reitera e ratifica o reconhecimento do estado de calamidade pública e a declaração de situação de emergência em saúde, altera dispositivos e prorroga prazos do Decreto ${ }^{\circ}$ 5.496, de 20 de março de 2020, que estabelece novas medidas para enfrentamento da emergência de saúde pública decorrente da doença COVID-19, causada pelo coronavírus SARS-CoV-2. Rio Branco, AC. Recuperado de http://diario.ac.gov. br/download.php?arquivo=KEQxQHI3IyEpRE8xN Tg3MTczMDU3MzM3OC5wZGY=

Decreto n. 9.472, de 17 de abril de 2020. (2020). Prorroga o prazo de vigência de medidas temporárias ao enfrentamento da emergência de saúde pública de importância internacional decorrente do novo coronavírus, vetor da COVID-19, e dá outras providências. João Pessoa, PB. Recuperado de http:// www.joaopessoa.pb.gov.br/portal/wp-content/ uploads/2020/04/2020_Ed_Especial-17_04.pdf

Decreto n. 14.271, de 29 de abril de 2020. (2020). Acrescenta dispositivos ao Decreto n. 14.232, de 3 de abril de 2020, que "Estabelece medidas de contenção da propagação de contágio do COVID-19 para as atividades e a prestação dos serviços relativos ao Sistema Municipal de Mobilidade Urbana", e dá outras providências. Campo Grande, MS. 
Recuperado de http://portal.capital.ms.gov.br/egov/ downloadFile.php?id=8042\&fileField=arquivo_dia_ ofi\&table=diario_oficial\&key=id_dia_ofi\&sigla_ sec $=$ diogrande

Decreto n. 17.326, de 06 de abril de 2020. (2020). Determina a proibição da circulação no território do Município de Belo Horizonte de transporte público coletivo oriundo de municípios que interromperem as medidas de isolamento social. Belo Horizonte, MG. Recuperado de http://portal6.pbh.gov.br/ dom/iniciaEdicao.do? method=DetalheArtigo\& $\mathrm{pk}=1227679$

Decreto n. 19.548, de 29 de março de 2020. (2020). Dispõe sobre o funcionamento das atividades de indústria, comércio, logística e sociais, para o atendimento mínimo às demandas da população de Teresina e do Poder Público, na vigência do "estado de calamidade pública", decorrente do novo coronavírus (COVID-19), no Município de Teresina, e dá outras providências. Teresina, PI. Recuperado de http://dom.pmt.pi.gov.br/admin/ upload/DOM2739-30032020-ASSINADO.pdf

Decreto n. 19.635, de 14 de abril de 2020. (2020). Altera o Decreto no 19.586 , de 27 de março de 2020, na forma que indica, e dá outras providências. Salvador, BA. Recuperado de http://diarios.egba. ba.gov.br/html/DO15/DO_frm0.html

Decreto n. 20.549, de 22 de abril de 2020. (2020). Altera os capita do art. $8^{\circ}$, do art. 10 e do art. 30 e inclui o parágrafo único no art. 10, todos do Decreto no 20.534, de 31 de março de 2020, que decreta o estado de calamidade pública em razão da pandemia de importância internacional decorrente do novo Coronavírus (COVID-19) e dá outras providências. Porto Alegre, RS. Recuperado de http://dopaonlineupload.procempa.com.br/ dopaonlineupload/3340_ce_288405_1.pdf

Decreto n. 21.357, de 19 de março de 2020. (2020). Proíbe o acesso à orla das praias, proíbe o tráfego de veículos de transporte coletivo e turístico de pessoas e dá outras providências. Florianópolis, SC. Recuperado de http://www.pmf.sc.gov.br/arquivos/ diario/pdf/19_03_2020_18.24.54.c52850576e811b4 883b2583a2a489f06.pdf

Decreto n. 24.979, de 26 de abril de 2020. (2020). Dispõe sobre o Estado de Calamidade Pública, regulamenta quarentena e restrição de serviços e atividades em todo o território do Estado de Rondônia e revoga o Decreto ${ }^{\circ} 24.919$, de 5 de abril de 2020. Porto Velho, RO. Recuperado de http:// www.diof.ro.gov.br/data/uploads/2020/04/DOE27.04.2020.pdf

Decreto n. 47.052, de 29 de abril de 2020. (2020). Dispõe sobre as medidas para enfrentamento da propagação decorrente do novo coronavírus (COVID-19), em decorrência da situação de emergência em saúde e dá outras providências. Rio de Janeiro, RJ. Recuperado de http://www.ioerj.com. $\mathrm{br} /$ portal/modules/conteudoonline/mostra_edicao. php?session=VWxWU1FrNXJSWGRSVkdOMFQx UldRazFwTURCU1JHczBURIZKZUUwd1NYUk9 WR3N6VDBSUmQxRIVVa1ZQVkdjMA==\&p=M $\mathrm{g}==\& \mathrm{tb}=$ NDcuMDUyJiMwMTM7

Decreto n. 48.834, de 20 de março de 2020. (2020). Define no âmbito socioeconômico medidas restritivas temporárias adicionais para enfrentamento da emergência de saúde pública de importância internacional decorrente do coronavírus. Recife, PE. Recuperado de https:// diariooficial.cepe.com.br/diariooficialweb/\#/ visualizar-jornal? dataPublicacao $=21$ - 03 2020\&diario $=\mathrm{MQ} \% 3 \mathrm{D} \% 3 \mathrm{D}$

Decreto n. 55.154, de $1^{\circ}$ de abril de 2020. (2020). Reitera a declaração de estado de calamidade pública em todo o território do Estado do Rio Grande do Sul para fins de prevenção e de enfrentamento à epidemia causada pelo COVID-19 (novo Coronavírus), e dá outras providências. Porto Alegre, RS. Recuperado de https://educacao.rs.gov. br/upload/arquivos/202004/01154835-decretocalamidade-publica-1.pdf

Decreto n. 59.283, de 16 de março de 2020. (2020). Declara situação de emergência no Município de São Paulo e define outras medidas para o enfrentamento da pandemia decorrente do coronavírus. São Paulo, SP. Recuperado de http://legislacao.prefeitura.sp.gov. br/leis/decreto-59283-de-16-de-marco-de-2020

De Vos, J. (2020, 24 de abril). The effect of COVID-19 and subsequent social distancing on travel behavior. Transportation Research Interdisciplinary Perspectives, 5, 100121. Recuperado de https://doi. org/10.1016/j.trip.2020.100121

Domingues, S., \& Zlatkovic, D. (2015). Renegotiating ppp contracts: reinforcing the 'p'in 
partnership. Transport Reviews, 35(2), 204-225. Recuperado de https://doi.org/10.1080/01441647. 2014.992495

Fletcher, K., Amarakoon, S., Haskell, J., Penn, P., Wilmoth, M., Matherly, D., \& Langdon, N. (2014). A guide for public transportation pandemic planning and response. Washington, DC: The National Academies Press. Recuperado de https://doi. org/10.17226/22414

Foye, P. J. (2020, 24 de março). The M.T.A. Needs Help. Now. The New York Times. Recuperado de https://www.nytimes.com/2020/03/24/opinion/ mta-new-york-transit.html?searchResultPosition $=7$

Goldbaum, C. (2020, 24 de março). Subway service is cut by a quarter because of coronavirus. The New York Times. Recuperado de https://www.nytimes. com/2020/03/24/nyregion/coronavirus-nyc-mtacuts-.html?searchResultPosition $=6$

Gómez-Lobo, A., \& Briones, J. (2014). Incentives in bus concession contracts: a review of several experiences in Latin America. Transport Reviews, 34(2), 246-265. Recuperado de https:// doi.org/10.1080/01441647.2014.895451

Gomide, A. A., \& Carvalho, C. H. R. de. (2016, março). Transformações e Tendências Recentes na Regulação dos Serviços de Ônibus Urbano no Brasil (Texto para Discussão n. 2197). Rio de Janeiro, RJ: Instituto de Pesquisa Econômica Aplicada. Recuperado de https://www.ipea.gov.br/ portal/images/stories/PDFs/chamadas_publicas/ promob/2016/td_2187.pdf

Gwilliam, K. (2008). Bus transport: is there a regulatory cycle? Transportation Research Part A: Policy and Practice, 42(9), 1183-1194. Recuperado de https://doi.org/10.1016/j.tra.2008.05.001

Justen, M., Filho. (2003). Teoria geral das concessões de serviço público. São Paulo, SP: Dialética.

King, D. A., \& Krizek, K. J. (2020). The power of reforming streets to boost access for human-scaled vehicles. Transportation Research Part D: Transport and Environment, 83, 102336. Recuperado de https:// doi.org/10.1016/j.trd.2020.102336

Laffont, J. J. (2005). Regulation and development. Cambridge, UK: Cambridge University Press. Recuperado de https://doi.org/10.1017/ CBO9781139163392
Laker, L. (2020, 11 de abril). World cities turn their streets over to walkers and cyclists. The Guardian. Recuperado de https://www.theguardian.com/ world/2020/apr/11/world-cities-turn-their-streetsover-to-walkers-and-cyclists?CMP=share_btn_tw

Lei n. 5.452, de $1^{\circ}$ de maio de 1943. (1943). Aprova a Consolidação das Leis do Trabalho. Rio de Janeiro, RJ. Recuperado de http://www.planalto.gov.br/ ccivil_03/decreto-lei/del5452.htm

Lei n. 8.987, de 13 de fevereiro de 1995. (1995). Dispõe sobre o regime de concessão e permissão da prestação de serviços públicos previsto no art. 175 da Constituição Federal, e dá outras providências. Brasília, DF. Recuperado de: http://www.planalto. gov.br/ccivil_03/leis/18987cons.htm

Lima, G. C. L. S., Schechtman, R., Brizon, L. C., \& Figueiredo, Z. M. (2020, abril). Transporte público e COVID-19. O que pode ser feito? Rio de Janeiro, RJ: Centro de Estudos em Regulação e Infraestrutura da Fundação Getulio Vargas. Recuperado de https:// ceri.fgv.br/sites/default/files/publicacoes/2020-04/ covid_e_mobilidade_urbana_fgv_ceri.pdf

Medida Provisória n.936, de $1^{\circ}$ de Abril de 2020. (2020). Institui o Programa Emergencial de Manutenção do Emprego e da Renda e dispõe sobre medidas trabalhistas complementares para enfrentamento do estado de calamidade pública reconhecido pelo Decreto Legislativo $n^{\circ}$ 6, de 20 de março de 2020, e da emergência de saúde pública de importância internacional decorrente do coronavírus (Covid-19), de que trata a Lei no 13.979, de 6 de fevereiro de 2020, e dá outras providências. Brasília, DF. Recuperado de http://www.planalto.gov.br/ccivil_03/_Ato20192022/2020/Mpv/mpv936.htm

Merkert, R., Preston, J., Melkersson, M., \& Link, H. (2018). Workshop 2 report: Competitive tendering and other forms of contracting-out: Institutional design and performance measurement. Research in Transportation Economics, 69, 86-96. Recuperado de https://doi.org/10.1016/j.retrec.2018.08.002

Mesentier, A. A. P., Malburg, C. H. R., Souza, F. O., Amicci, A. G. N., \& Santos, R. T. dos. (2018). Panorama setorial 2015-2018: mobilidade urbana. Rio de Janeiro, RJ: Banco Nacional do Desenvolvimento. Recuperado de https://web. bndes.gov.br/bib/jspui/bitstream/1408/14960/1/ Mobilidade\%20urbana_P_BD.pdf 
Metrô-SP. (2019, julho). Pesquisa Origem Destino 2017. 50 Anos. A Mobilidade Urbana da Região Metropolitana de São Paulo em Detalhes. São Paulo, SP: Companhia do Metropolitano de São Paulo. Recuperado de http://www.metro.sp.gov. br/pesquisa-od/arquivos/Ebook\%20Pesquisa\%20 OD\%202017_final_240719_versao_4.pdf

Moovit. (2020). Impact of coronavirus (COVID-19) on public transit usage. Recuperado de https:// moovitapp.com/insights/en/Moovit_Insights_ Public_Transit_Index-countries

Norma Complementar CETURB/ES n. 003, de 2020. (2020). Dispõe sobre medidas de caráter excepcional e temporário às empresas transportadoras que operam sob delegação do Estado do Espírito Santo, os Serviços Autorizados e Concessionados, no âmbito do Sistema de Transporte Rodoviário Intermunicipal de Passageiros do Estado do Espírito Santo - SITRIP/ ES, para enfrentamento da emergência de saúde pública decorrente do coronavírus (COVID-19). Vitória, ES. Recuperado de https://ceturb.es.gov. br/Media/ceturb/Legisla\%C3\%A7\%C3\%A3o/ Norma\%20Complementar\%20003-2020.pdf

Norma Complementar CETURB/ES n. 004, de 2020. (2020). Altera a Norma Complementar no 03/2020, de 19 de março de 2020, e dá outras providências no âmbito do enfrentamento da emergência de saúde pública decorrente da infecção humana pelo novo coronavirus (COVID-19). Vitória, ES. Recuperado de https://ceturb.es.gov.br/Media/ ceturb/Legisla \%C3\%A7\%C3\%A3o/Norma\%20 Complementar\%20004-2020.pdf

Organização para a Cooperação e Desenvolvimento Econômico. (2013, fevereiro). Methods for Allocating Contracts for the Provision of Regional and Local Transportation Services. Recuperado de http://www. oecd.org/daf/competition/

Pereira, R. H. M., Braga, C. K. V., Servo, L. M., Serra, B., Amaral, P., \& Gouveia, N. (2020, abril). Nota Técnica 14. Mobilidade Urbana e o Acesso ao Sistema Único de Saúde para Casos Suspeitos e Graves de COVID-19 nas Vinte Maiores Cidades do Brasil. Brasília, DF: Instituto de Pesquisa Econômica Aplicada. Recuperado de https://www.ipea.gov.br/ portal/images/stories/PDFs/nota_tecnica/200408_ nota_tecnica_14_dirur.pdf
Portaria Detro/Pres n. 1.523, de 06 de abril de 2020. (2020). Dispõe sobre alteração no inciso VIII, do Art. $4^{\circ}$ do Decreto No 47.006, de 27 de Março de 2020, em decorrência da emergência de saúde pública de importância internacional decorrente do coronavírus (COVID-19), e dá outras providências. Rio de Janeiro, RJ. Recuperado de http://www.ioerj. com.br/portal/modules/conteudoonline/mostra edicao.php?session=VVdwVmVVNVZVa1pSVkZG MFRtcEZlazFwTURCTIJFa3dURIZLUms5RWEzU 1JhMFV5VG10Uk1GSIVSVFZQUlZwQw $==\& \mathrm{p}=\mathrm{M}$ $\mathrm{TM}=\& \mathrm{tb}=\mathrm{cG}$ 9ydGFyaWEgZGV0cm8mIzAxMzs=

Portaria Smpu/Gab n. 008, de 2020. (2020). Torna sem efeito a portaria n. 07 de 03 abril de 2020 e altera e consolida as portarias $03,04,05$ e 06 publicadas entre os dias 19 de março de 2020 a 26 de março de 2020, que estabelecem medidas emergenciais no âmbito da secretaria municipal de mobilidade e planejamento urbano de Florianópolis (SMPU). Florianópolis, SC. Recuperado de http://www.pmf. sc.gov.br/arquivos/diario/pdf/03_04_2020_19.44.18 .1e5c7afb3244c38f3996538251c95f12.pdf

Resolução Conjunta SEDEERI/SETRANS n. 11, de 07 de Abril de 2020. (2020). Disciplina as restrições de circulação de pessoas no transporte intermunicipal de passageiros no estado do Rio de Janeiro, e dá outras providências. Rio de Janeiro, RJ. Recuperado de http://www.ioerj.com.br/portal/modules/ conteudoonline/mostra_edicao.php?session $=\mathrm{VVd}$ wVmVVNVZValpSVkZGMFRtcEZlazFwTURCT 1JFa3dURlZLUms5RWEzUlJhMFV5VG10Uk1GSl VSVFZQU1ZwQw $==\& \mathrm{p}=\mathrm{OA}==\& \mathrm{tb}=\mathrm{cmVzb} 2 \mathrm{x} 1 \mathrm{w}$ 6fDo28gY29uanVudGEmIzAxMzs=

Rolim, F., Brasileiro, A., \& Santos, E. (2010). Competition in Brazilian bus and coach services - The results of recent competitive tendering processes. Research in Transportation Economics, 29(1), 45-51.

Roy, W., \& Yvrande-Billon, A. (2007). Ownership, contractual practices and technical efficiency: The case of urban public transport in France. Journal of Transport Economics and Policy (JTEP), 41(2), 257-282.

Tirole, J. (1999). Incomplete contracts: Where do we stand?. Econometrica, 67(4), 741-781.

Troko, J., Myles, P., Gibson, J., Hashim, A., Enstone, J., Kingdon, S., ... Van-Tam, J. N. (2011). Is public 
transport a risk factor for acute respiratory infection? BMC infectious diseases, 11(16), 1-6.

Union Internationale des Transport Publics. (2020, Fevereiro). Management of COVID-19 Guidelines for Public Transport Operators. Recuperado de https:// www.uitp.org/management-covid-19-guidelinespublic-transport-operators
Van de Velde, D., Beck, A., Van Elburg, J., \& Terschüren, K. H. (2008). Contracting in urban public transport. Amsterdam, The Netherlands: European Commission, 123. Recuperado de https://ec.europa. eu/transport/sites/transport/files/themes/urban/ studies/doc/2008_contracting_urban_public_ transport.pdf

\section{Gregório Costa Luz de Souza Lima}

https://orcid.org/0000-0002-1041-6179

Mestrando no Programa de Engenharia de Transportes da Universidade Federal do Rio de Janeiro (PET/ COPPE). E-mail: gregorioluz@pet.coppe.ufrj.br

\section{Gabriel Stumpf Duarte de Carvalho}

https://orcid.org/0000-0002-8333-7789

Pesquisador no Departamento de Engenharia Civil, Arquitetura e Georecursos (DECivil) do Instituto Superior Técnico de Lisboa (IST - Lisboa). E-mail: gabrielstumpf@tecnico.ulisboa.pt

\section{Miguel Zobaran Figueiredo}

https://orcid.org/0000-0001-8313-3834

Assistente de pesquisa no Centro de Estudos em Regulação e Infraestrutura da Fundação Getulio Vargas (FGV CERI). E-mail: miguel.figueiredo@fgv.br 